\title{
Produção de forragem e potencial de utilização do capim faixa-branca submetido a frequências de desfolhação
}

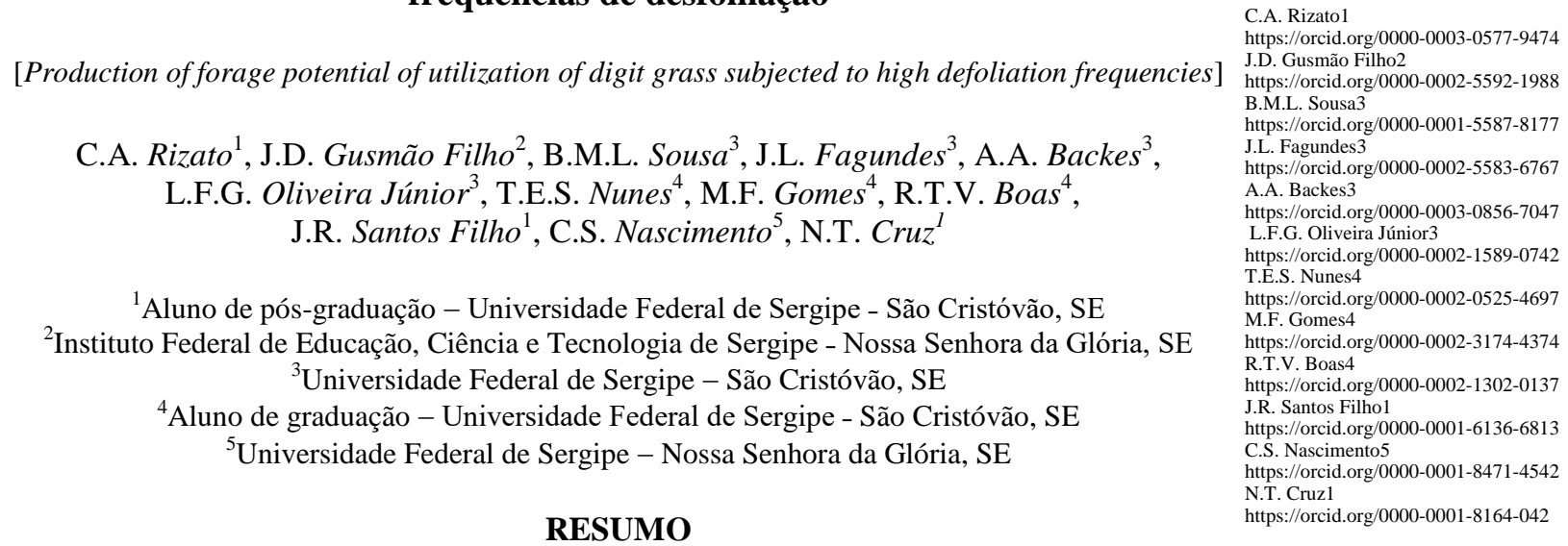

O objetivo deste trabalho foi avaliar a produção de forragem e o potencial de utilização do capim faixabranca submetido a frequências de desfolhação. Os tratamentos foram constituídos de quatro frequências de desfolhação: muito alta $(25 \mathrm{~cm})$, alta $(35 \mathrm{~cm})$, média $(45 \mathrm{~cm})$ e baixa $(55 \mathrm{~cm})$, avaliados em duas épocas do ano (maior e menor insolação), entre 2015 e 2016. Utilizou-se o delineamento em blocos ao acaso, com quatro repetições e medidas repetidas no tempo. A produção diária de folhas foi menor na frequência muito alta em relação às outras frequências. A redução das frequências de desfolhação aumentou a produção diária de colmo, senescência diária de folhas, produção total diária e acúmulo líquido diário de forragem e diminuiu o potencial de utilização da forragem. No período de maior insolação, a produção diária de colmos, o acúmulo líquido diário de forragem e o potencial de utilização de forragem foram maiores e a senescência diária de folhas foi menor. A frequência de desfolhação muito alta não proporcionou um bom desenvolvimento da planta, enquanto a frequência baixa apresentou elevada produção de colmos. As frequências de desfolhação alta e média são mais indicadas para a desfolhação do capim faixa-branca, promovendo uma melhor proporção de folhas em relação a colmos.

Palavras-chave: altura de cortes, Digitaria eriantha, manejo racional, pastagem irrigada

\begin{abstract}
The objective of this study was to evaluate the production of forage and the potential of utilization of digit grass subjected to four defoliation frequencies: very high $(25 \mathrm{~cm})$, high $(35 \mathrm{~cm})$, medium $(45 \mathrm{~cm})$, and low $(55 \mathrm{~cm})$, evaluated at two times of the year (higher and lower insolation), from January 2015 to January 2016. A randomized-block design with four replicates was adopted and measures repeated over time. The daily production of leaves was lower at the very high frequency in relation to the other frequencies. The reduction in defoliation frequency increased the daily production of stems, the daily leaf senescence, the total daily forage production, and the daily forage accumulation, and decreased the potential of forage utilization. At the time of higher insolation, the daily production of stems, the daily forage accumulation, the potential of utilization of forage were higher, and the daily leaf senescence was lower. The very high frequency of defoliation did not provide a good development of the plan, while the lower frequency displayed a high production of stems. The high and medium frequencies of defoliation are more indicated to the defoliation of digit grass, enabling a better proportion of leaves in relation to stems.
\end{abstract}

Keywords: Digitaria eriantha, harvest height, irrigated pasture, rational management

Recebido em 13 de setembro de 2017

Aceito em 17 de abril de 2018

E-mail: rizato.cesar@gmail.com 


\section{INTRODUÇÃO}

O Brasil possui aproximadamente 196 milhões de hectares com pastagens (Food..., 2017). Apesar da sua importância para a produção animal no país, os pastos no Brasil, na sua maioria, são manejados de maneira inadequada e ineficiente. Nesse sentido, torna-se essencial o aprimoramento das técnicas de manejo para cada gramínea, visando colheitas mais eficientes e o equilíbrio entre quantidade e qualidade.

Atualmente, as pesquisas realizadas com pastagem no Brasil focam o conhecimento do processo de acúmulo de forragem, por meio do entendimento de como a planta cresce e se desenvolve, bem como a compreensão das modificações morfofisiológicas que ocorrem em virtude do corte, do pastejo, da adubação, da irrigação, entre outros, em razão das alterações climáticas ao longo do ano (Silva e Nascimento Jr., 2007). Esses estudos têm demonstrado que cada planta forrageira apresenta exigências específicas de manejo, como alturas de entrada e saída de animais em lotação rotativa. Tal conhecimento tem colaborado para a determinação de manejos mais racionais das pastagens para diversas plantas forrageiras, como os capins mombaça, tanzânia, marandu, braquiária, mulato, cameroon (Nascimento Jr. et al., 2010), entre outros.

Mesmo que seja crescente a produção científica nessa área, diversas plantas forrageiras ainda apresentam escassas informações técnicas em relação ao seu manejo, gerando, assim, demanda por pesquisas, como é o caso da Digitaria eriantha cv. Suvernola, conhecida popularmente como capim faixa-branca (Cook e SchultzeKraft, 2015). Essa gramínea, que atualmente é mais difundida no Nordeste brasileiro, especialmente em Sergipe e Alagoas (Souza et al., 2016), apresenta-se adaptada a regiões com baixa precipitação pluviométrica e a solos de baixa fertilidade natural (Navarro et al., 2005), apesar de mostrar-se responsiva à irrigação (Oliveira et al., 2015) e à adubação nitrogenada (Souza et al., 2016).

Embora o capim faixa-branca apresente importância regional, a utilização dele ainda é limitada quando comparado a outras plantas forrageiras. Em parte, isso ocorre devido ao escasso conhecimento acerca das modificações morfofisiológicas e produtivas do capim faixabranca quando manejado com distintas metas de desfolhação, notadamente nas condições edafoclimáticas do Nordeste brasileiro. Esse conhecimento poderá auxiliar na definição de metas racionais de manejo para essa gramínea.

Assim, o objetivo deste trabalho foi avaliar a produção diária de forragem e dos componentes morfológicos, bem como o potencial de utilização do capim faixa-branca submetido a frequências de desfolhação em distintas épocas do ano.

\section{MATERIAL E MÉTODOS}

O experimento foi conduzido, no período de março de 2015 a março de 2016, em área cultivada com o capim faixa-branca (Digitaria eriantha cv. Suvernola), na Universidade Federal de Sergipe - UFS, no município de São Cristóvão/SE (11 $\left.{ }^{\circ} 22^{\prime} \quad \mathrm{S} ; 3^{\circ} 12^{\prime} \quad \mathrm{W} ; 47 \mathrm{~m}\right)$. Segundo a classificação de Köppen, o clima da região é do tipo Awa, tropical, com período seco nos meses de setembro a março e período chuvoso de abril a agosto. A temperatura e a pluviosidade média anual são de $25,6^{\circ} \mathrm{C}$ e $1.409 \mathrm{~mm}$, respectivamente. A insolação total mensal, as médias mensais de temperatura mínima, média e máxima (Fig. 1) e a precipitação total mensal (Fig. 2), ao longo do período experimental, foram obtidas no Instituto Nacional de Meteorologia.

O solo da área experimental foi classificado como Neossolo Quartzarênico de textura arenosa, relevo plano, o qual apresentava as seguintes características químicas: $\mathrm{pH}$ em água=5,49; $\mathrm{P}$ (Mehlich-1)=3,90 e K=138mg.dm 3; $\mathrm{Ca}=0,38 ; \mathrm{Mg}=0,35 ; \mathrm{H}+\mathrm{Al}=1,24 ; \mathrm{SB}=1,21 \mathrm{e}$ CTC $(\mathrm{pH} \mathrm{7,0})=2,45 \mathrm{cmolc} . \mathrm{dm}^{-3}$; e $\mathrm{MO}=11,8 \mathrm{~g} . \mathrm{dm}^{-}$ ${ }^{3}$. Com base nas características químicas do solo, foram aplicados, no início do período experimental, 100kg.ha- ${ }^{-1}$ de $\mathrm{P}_{2} \mathrm{O}_{5}$ na forma de superfosfato simples, $100 \mathrm{~kg} \cdot \mathrm{ha}^{-1}$ de $\mathrm{K}_{2} \mathrm{O}$ na forma de cloreto de potássio e $60 \mathrm{~kg} \cdot \mathrm{ha}^{-1}$ de $\mathrm{N}$ na forma de ureia. 


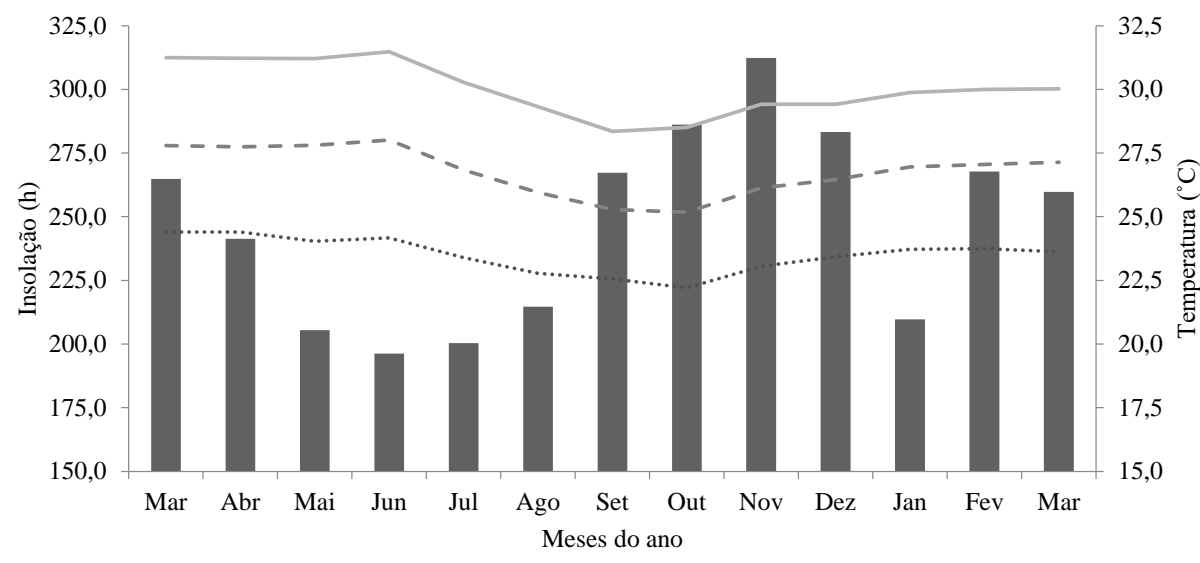

Insolação —Temperatura Máxima - - - Temperatura Média ……. Temperatura Mínima

Figura 1. Insolação total mensal (h) e temperaturas mínima, média e máxima $\left({ }^{\circ} \mathrm{C}\right)$ no período de março de 2015 a março de 2016.

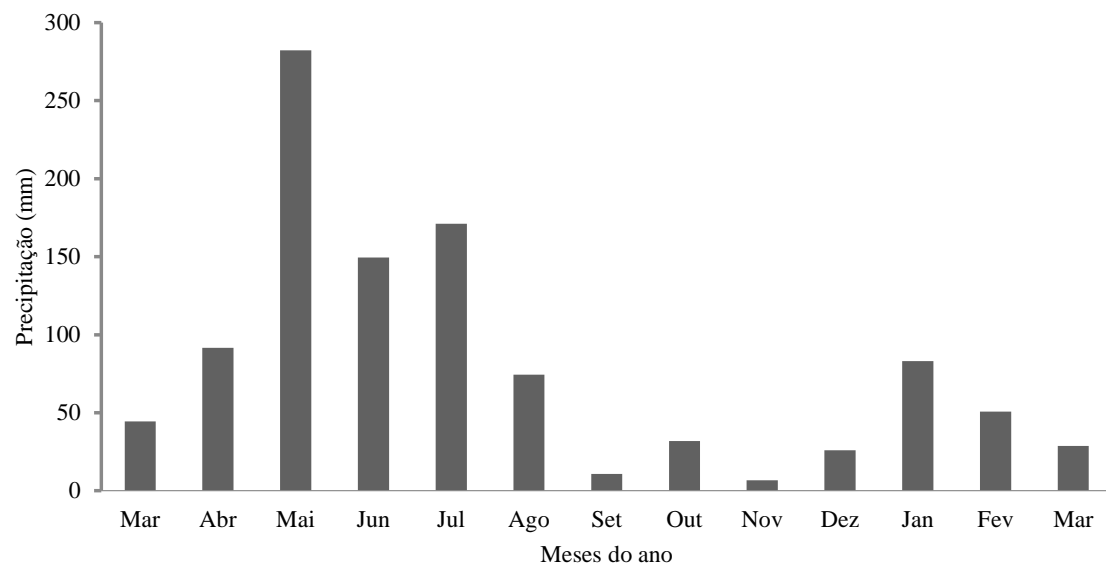

Figura 2. Precipitação total mensal (mm) de março de 2015 a março de 2016.

No início do período experimental, o capim faixa-branca sofreu corte de nivelamento, por meio do qual as plantas de todas as parcelas foram rebaixadas para $10 \mathrm{~cm}$, marcando, assim, $o$ início das avaliações. Os tratamentos constituíram quatro frequências de desfolhação: muito alta (desfolhação quando atingia $25 \mathrm{~cm}$ de altura), alta $(35 \mathrm{~cm})$, média $(45 \mathrm{~cm})$ e baixa $(55 \mathrm{~cm})$. O capim faixa-branca era rebaixado a $10 \mathrm{~cm}$ de altura de resíduo pós-corte. As frequências de desfolhação foram avaliadas em dois períodos do ano: menor insolação (abril a agosto) e maior insolação (setembro a março). O delineamento experimental foi em blocos ao acaso, com quatro repetições e medidas repetidas no tempo. As unidades experimentais foram irrigadas regularmente ao longo de todo o período experimental.
A adubação de produção foi realizada com $300 \mathrm{~kg} \cdot \mathrm{ha}^{-1} \cdot$ ano $^{-1}$ de nitrogênio (sulfato de amônio), conforme recomendação de Souza et al. (2016) para o capim faixa-branca, na forma de 240kg.ha ${ }^{-1}$.ano ${ }^{-1}$ de potássio (cloreto de potássio). A adubação foi realizada de maneira parcelada, após o corte, de acordo com o intervalo entre cortes, segundo recomendação de Sousa et al. (2013). A altura dossel foi determinada com régua, correspondendo à média de cinco pontos por unidade experimental.

Logo após cada corte, no início da rebrotação, eram marcados cinco perfilhos basais por unidade experimental. Esses perfilhos tiveram seu crescimento e desenvolvimento acompanhados a cada sete dias, quando eram realizadas medições de alongamento de lâminas 
foliares e do pseudocolmo (colmo e bainhas foliares) e senescência de lâminas foliares. Adicionalmente, os perfilhos aéreos surgidos ao longo da rebrotação, nos cinco perfilhos marcados inicialmente, também foram monitorados. Essas avaliações possibilitaram estimar as taxas de alongamento de folhas e de colmos e as taxas de senescência de folhas (cm.perfilho ${ }^{-1} \cdot \mathrm{dia}^{-1}$ ) (Lemaire e Chapman, 1996).

Os valores lineares (cm) das taxas de alongamento e senescência foram convertidos em valores de peso por unidade de área utilizando-se um fator de conversão. No último dia de cada período de avaliação, todos os perfilhos marcados eram cortados em nível do solo (perfilhos basais) ou no ponto de inserção (perfilhos aéreos). Esses perfilhos eram colocados em sacos plásticos e levados imediatamente à câmara fria para minimizar perdas por respiração e evaporação. Após a medição de colmos e folhas de forma análoga àquela realizada no campo, todas as lâminas foliares de cada perfilho e seus respectivos colmos foram levados para estufa de ventilação forçada de ar a $65^{\circ} \mathrm{C}$ por $72 \mathrm{~h}$. Após a secagem, o material era pesado e a massa de cada componente era dividida pelo seu respectivo comprimento total. Gerou-se, portanto, um fator de conversão $\left(\mathrm{mg} . \mathrm{cm}^{-1}\right)$ utilizado para transformar todas as leituras de campo, expressas em $\mathrm{cm} /$ perfilho.dia, em mg.perfilho ${ }^{-1} \cdot \mathrm{dia}^{-1}$. A transformação final para $\mathrm{kg} \cdot \mathrm{ha}^{-1} \cdot \mathrm{dia}^{-1}$ de massa seca de forragem foi realizada multiplicando-se esses valores pela densidade populacional de perfilhos em cada unidade experimental. Esta foi obtida por meio da contagem dos perfilhos vivos existentes no interior de quatro armações metálicas de $0,50 \mathrm{~m}^{2}$, posicionadas em pontos representativos da condição média do dossel antes da realização dos cortes. Dessa maneira, os valores lineares das taxas de alongamento de folhas, colmos e de senescência foram transformados em produção diária de folhas e de colmos e senescência diária de folhas (kg.ha ${ }^{1}$.dia ${ }^{-1}$ de MS). A soma da produção diária de folhas e de colmos deu origem à produção diária de forragem, e a diferença entre os valores de produção diária de forragem e senescência foliar possibilitou o cálculo do acúmulo diário de forragem. A partir dos valores da produção diária de forragem e de senescência, foi possível estimar o potencial de utilização da forragem [(1- senescência x produção de forragem ${ }^{-1}$ ) x 100] (Bircham e Hodgson, 1983).

Os dados foram organizados de acordo com os meses do ano e submetidos à análise de variância utilizando-se o procedimento MIXED do pacote estatístico SAS (Statistical Analysis System). As médias entre os tratamentos foram estimadas mediante o uso do procedimento LSMEANS e comparadas por meio da probabilidade da diferença (PDIFF) utilizando-se o teste " $\mathrm{t}$ " de Student, com significância de 5\%.

\section{RESULTADOS E DISCUSSÃO}

As frequências de desfolhação ficaram próximas às alturas pretendidas, com média de $26,2 \mathrm{~cm}$ para a frequência muito alta; $35,5 \mathrm{~cm}$ para a frequência alta; $45,8 \mathrm{~cm}$ para a frequência média; e $54,4 \mathrm{~cm}$ para a frequência baixa, mostrando, assim, um adequado controle das condições experimentais.

A produção diária de folhas foi influenciada $(\mathrm{P}<0,05)$ apenas pelas frequências de desfolhação. A menor produção de folhas do capim faixa-branca foi encontrada na frequência muito alta em relação às demais frequências (Fig. 3).

As respostas das plantas ao distúrbio da desfolhação devem ser entendidas como mecanismo de restabelecimento e manutenção dos padrões de crescimento, em que todos os fatores disponíveis devem ser usados para a formação de novos tecidos fotossintetizantes (Lemaire e Chapman, 1996). Como todos os cortes foram realizados a $10 \mathrm{~cm}$ de altura de resíduo, possivelmente a frequência de desfolhação muito alta $(25 \mathrm{~cm})$ não permitiu que a planta atingisse seu índice de área foliar crítico (95\% de interceptação luminosa), o que pode ter limitado sua eficiência fotossintética e, consequentemente, sua produção de folhas (Nascimento Jr. et al., 2010). Este padrão pode indicar que uma desfolhação muito alta pode não ser recomendada para o manejo do capim faixabranca, por não permitir que a planta atinja seu potencial de utilização de folhas. Uma elevada quantidade de folhas no dossel forrageiro é desejável, pois este é um componente que apresenta melhores valores nutricionais (Araújo et al., 2017), sendo preferencialmente consumido por animais em pastejo (Gimenes et al., 2011). 


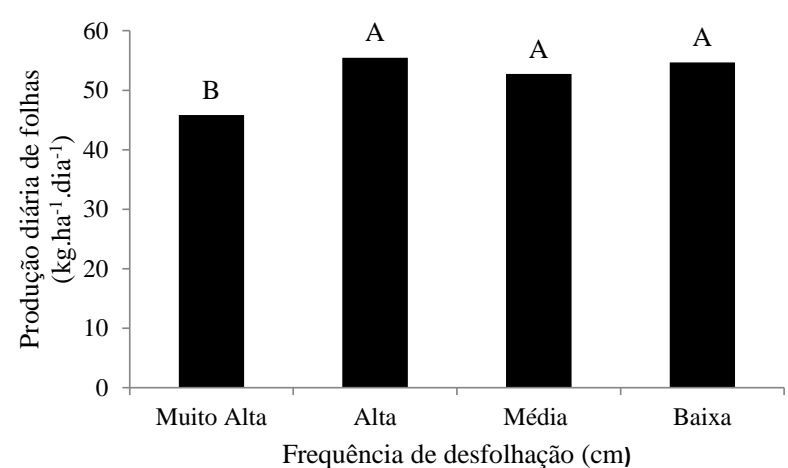

Figura 3. Produção diária de folhas do capim faixa-branca submetido a frequências de desfolhação.

Por outro lado, as frequências de desfolhação alta $(35 \mathrm{~cm})$, média $(45 \mathrm{~cm})$ e baixa $(55 \mathrm{~cm})$ não diferiram entre si em relação à produção diária de folhas. Esse fato sugere não haver vantagens produtivas, em termos de acúmulo de lâminas foliares, em prolongar demasiadamente o período de rebrotação do dossel, indicando que uma frequência de desfolhação baixa $(55 \mathrm{~cm}$ de altura) também pode não ser recomendada para o capim faixa-branca. Vale ressaltar ainda que desfolhações mais frequentes reduzem o período de descanso do pasto e, consequentemente, proporcionam maior renovação de perfilhos (Matthew et al., 2000). Nesse contexto, perfilhos jovens apresentam maiores taxas de crescimento e desenvolvimento comparativamente a perfilhos mais maduros (Paiva et al., 2011; Montagner et al., 2011), o que pode interferir diretamente na qualidade da forragem do pasto (Gimenes et al., 2011).

A produção diária de colmos foi influenciada $(\mathrm{P}<0,05)$ pelas frequências de desfolhação e pelas épocas do ano. A redução das frequências de desfolhação aumentou a produção de colmos do capim faixa-branca (Fig. 4A). Por sua vez, maior produção de colmo foi registrada no período de maior insolação (Fig. 4B).
A

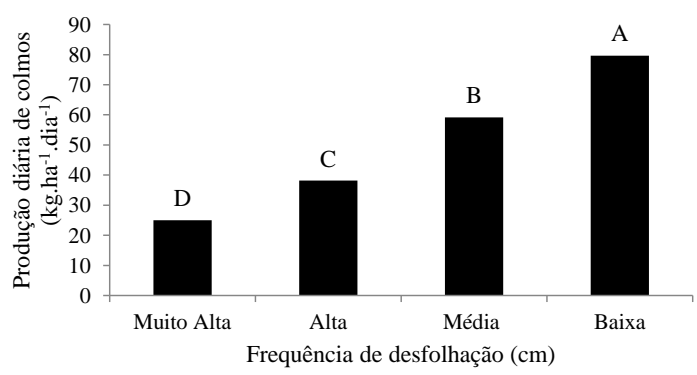

B

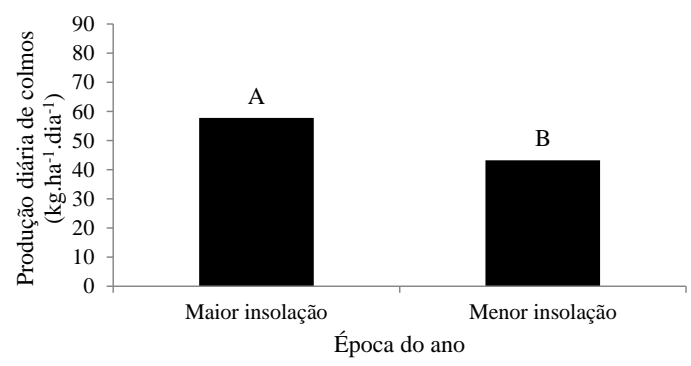

Figura 4. Produção diária de colmos do capim faixa-branca submetido a frequências de desfolhação (A) e a épocas do ano (B).

Pastos mais altos (desfolhações menos frequentes) apresentam maior competição intraespecífica por luz, reduzindo a quantidade e a qualidade da luz que penetra no interior do dossel, o que estimula o alongamento e o espessamento do colmo (Silva e Nascimento Jr., 2007), e isso, por conseguinte, aumentou a produção diária de colmos do capim faixabranca. Esse mesmo padrão de crescimento também foi registrado em outras plantas forrageiras, como os capins cameroon (Voltolini et al., 2010), marandu (Gimenes et al., 2011), mulato (Silveira et al., 2016), entre outros. Vale ressaltar ainda que a produção diária de colmos na menor frequência $(55 \mathrm{~cm})$ foi $319 \%$ maior em relação à maior frequência $(25 \mathrm{~cm})$, o que pode afetar negativamente o desempenho animal em pastejo. O colmo é um componente de menor valor nutritivo comparativamente às lâminas foliares (Gimenes et al., 2011). Adicionalmente, 
o colmo é considerado um componente que pode restringir o consumo voluntário de forragem, devido ao impedimento físico que este impõe sobre o processo de pastejo, podendo comprometer a eficiência de utilização da forragem (Difante et al., 2011). Este fato também indica que a frequência de desfolhação baixa $(55 \mathrm{~cm})$ pode não ser adequada para o manejo dessa planta.

A produção diária de colmos foi $34 \%$ maior no período de maior insolação em relação ao período de menor insolação (Fig. 4B). A maior produção diária de colmos no período de maior insolação pode ser decorrente da maior temperatura média, maior luminosidade (Fig. 1) e menor nebulosidade, resultante da menor precipitação (Fig. 2). De fato, mesmo não apresentando diferença estatística $(\mathrm{P}>0,05)$, a produção diária de folhas no período de maior insolação foi $8,5 \%$ maior em relação ao período de menor insolação, demonstrando a maior taxa de crescimento e desenvolvimento do dossel, neste período. Além disso, o capim faixa-branca é classificado como uma planta $\mathrm{C} 4$, que responde muito favoravelmente à maior quantidade de luz, desde que não haja restrição no suprimento de água, nutrientes, entre outros, contribuindo, assim, para as maiores taxas de crescimento encontradas no período de maior insolação.

A senescência diária de folhas do capim faixabranca foi influenciada $(\mathrm{P}<0,05)$ pelas frequências de desfolhação e pelas épocas do ano. A redução nas frequências de desfolhação aumentou a senescência diária de folhas do capim faixa-branca (Fig. 5A). Por sua vez, a maior senescência diária de folhas foi registrada no período de menor insolação em comparação ao período de maior insolação (Fig. 5B).
A

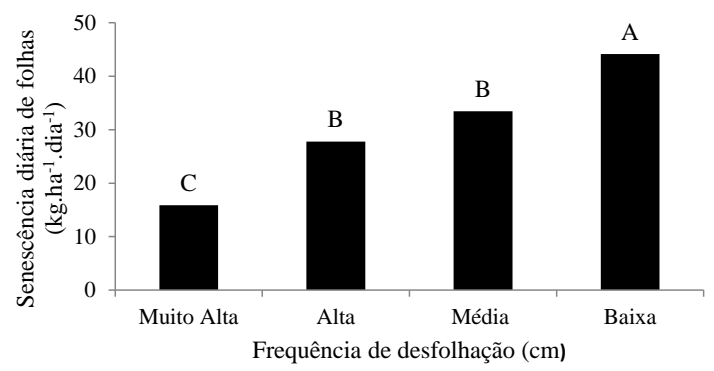

B

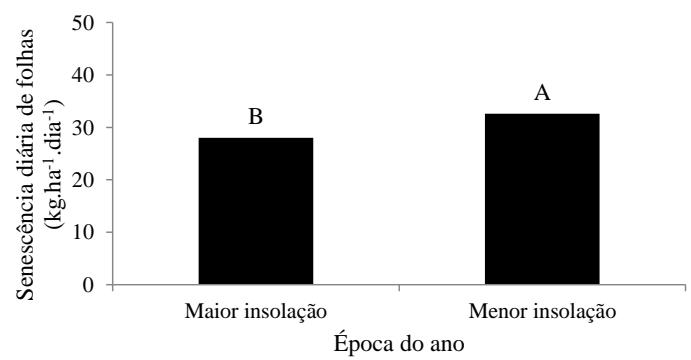

Figura 5. Senescência diária de folhas no capim faixa-branca submetido a frequências de desfolhação (A) e a épocas do ano (B).

A senescência pode ser desencadeada por diversos fatores, como ataque de pragas e doenças, modificações nas condições climáticas (temperatura, luminosidade, disponibilidade de água), idade da planta, competição por luz, entre outros (Taiz e Zeiger, 2009). Pastos mais altos apresentam maior competição intraespecífica por luz, o que aumenta o sombreamento das folhas localizadas na parte inferior do dossel (Silva e Nascimento Jr., 2007), desencadeando o processo de senescência foliar (Taiz e Zeiger, 2009). Este fato também indica que desfolhações pouco frequentes $(55 \mathrm{~cm})$ não representam uma vantagem produtiva para o capim faixa-branca, por acelerarem muito a senescência de folhas, não sendo, portanto, indicadas para o manejo dessa planta.
Em uma visão holística, a redução na frequência de desfolhação do capim faixa-branca não incrementou a produção diária de folhas (Fig. 3). O que ocorreu foi o aumento da produção diária de colmos (Fig. 4A) e o da senescência diária de folhas (Fig. 5A). Assim, o processo de sombreamento (competição intensa por luz) certamente inibiu a ativação de gemas axilares dormentes que poderiam desenvolver novos perfilhos e folhas (Matthew et al., 2000), desencadeou o processo de mortalidade de folhas e perfilhos (Matthew et al., 2000; Sbrissia e Silva, 2008) e o processo de alongamento de colmos (Silva e Nascimento Jr., 2007).

Por sua vez, o capim faixa-branca apresentou maior senescência diária de folhas no período de menor insolação. Nesse período, o intervalo entre desfolhações (período de descanso) foi de 37,0 
dias em comparação ao período de maior insolação (31,5 dias). Nesse caso, longevidade da folha pode estar determinando o padrão de resposta. As folhas apresentam um tempo de vida limitado e, após um determinado tempo, elas invariavelmente entram em processo de senescência. Assim, todo o material não colhido ou não pastejado é logo perdido por meio do processo de senescência, constituindo perdas potenciais de produção (Bircham e Hodgson, 1983). O intervalo de desfolhação de 37 dias pode estar sendo relativamente maior que a duração de vida das folhas do capim faixa- branca, o que invariavelmente pode estar causando a maior senescência diária de folhas no período de menor insolação. Essa variação na duração de vida da folha em distintas condições climáticas também foi relatada para os capins braquiária (Santos et al., 2011), marandu (Carvalho et al., 2016), entre outros.

A produção total diária foi influenciada $(\mathrm{P}<0,05)$ apenas pelas frequências de desfolhação. A redução nas frequências de desfolhação aumentou a produção total do capim faixa-branca (Fig. 6).

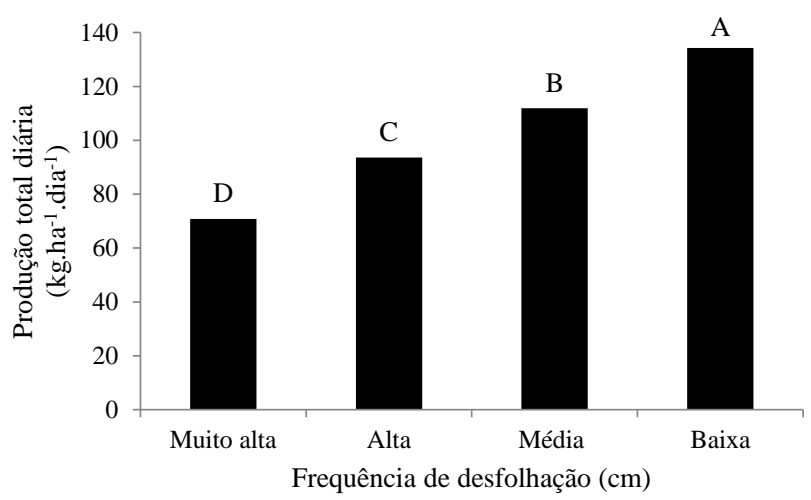

Figura 6. Produção total diária do capim faixa-branca submetido a frequências de desfolhação.

Como a produção diária de folhas (Fig. 3) não diferiu entre as frequências de desfolhação alta, média e baixa, certamente essa elevação na produção total diária (Fig. 6) deve-se à maior produção diária de colmos (Fig. 4A). Assim, o aumento na produção diária total com a redução na frequência de desfolhação é acompanhado de uma diminuição na relação lâmina/colmo do capim faixa-branca, o que reduz o valor nutritivo do pasto (Voltolini et al., 2010). Esse fato realça que manejar o capim faixa-branca com baixa

A

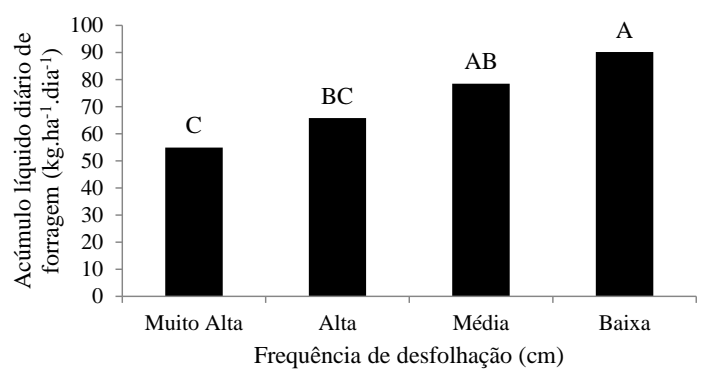

frequência de desfolhação $(55 \mathrm{~cm})$ pode não ser adequado.

O acúmulo líquido diário de forragem foi influenciado $(\mathrm{P}<0,05)$ pelas frequências de desfolhação e pelas épocas do ano. A redução nas frequências de desfolhação aumentou $\mathrm{O}$ acúmulo diário de forragem do capim faixabranca (Fig. 7A). Por sua vez, maior acúmulo foi registrado no período de maior insolação em comparação com o período de menor insolação (Fig. 7B).

B

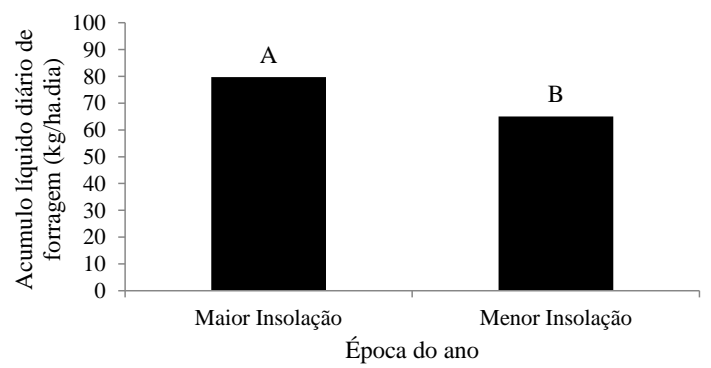

Figura 7. Acúmulo líquido diário de forragem do capim faixa-branca submetido a frequências de desfolhação (A) e a épocas do ano (B). 
O acúmulo líquido de forragem pode ser mais bem compreendido ao se avaliarem, de forma conjunta, dois aspectos intimamente relacionados, perfilhos individuais e a população de perfilhos. Ao se analisarem os processos que ocorrem em nível de perfilho individual, o acúmulo é resultado da diferença de crescimento de folhas e colmos e senescência foliar. Porém, pastagens são formadas por uma população de perfilhos, assim o acúmulo é determinado também pelas mudanças no número de perfilhos ligados aos processos de crescimento e senescência foliar em perfilhos individuais. Dessa forma, as interações entre esses dois níveis irão resultar no acúmulo líquido de forragem. Embora o acúmulo líquido diário de forragem tenha aumentado com a redução das frequências de desfolhação, a contribuição de colmos também se mostrou relativamente maior (Fig. 4A) nessa frequência. Como já sugerido anteriormente, essa menor frequência de desfolhação pode ser excessiva para iniciar a desfolhação do capim faixa-branca.

A

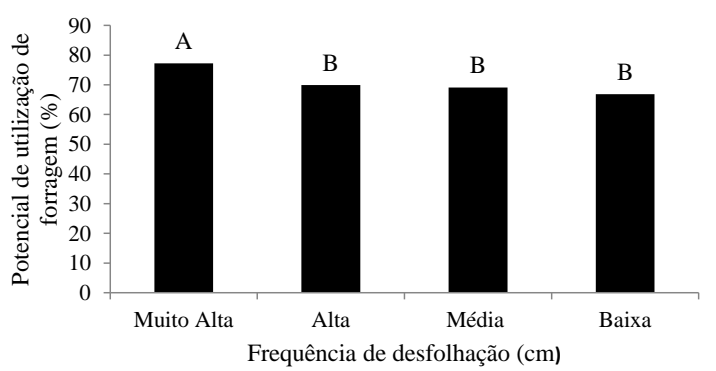

Figura 8. Potencial de utilização de forragem no capim faixa-branca submetido a frequências de desfolhação (A) e a épocas do ano (B).

O manejo com maior frequência de desfolhação $(25 \mathrm{~cm})$ apresentou maior potencial de utilização de forragem em relação às outras frequências. Esse resultado indica que, mesmo produzindo menor quantidade diária total de forragem (Fig. 6), maior proporção dessa forragem estaria disponível para o animal em pastejo, uma vez que as perdas por senescência diária também foram menores (Fig. 5A). Nesse contexto, ainda que o acúmulo líquido diário de forragem (Fig. 7A) do capim faixa-branca apresente-se maior quando as desfolhações são menos frequentes (maiores alturas), metas de manejo com alturas excessivamente elevadas podem ser indesejáveis, visto o acentuado acúmulo de colmos e forragem morta.
O acúmulo líquido diário de forragem foi maior na época de maior insolação em relação ao período de menor insolação. No período de maior insolação, a produção diária de folhas foi $8,5 \%$ maior, o acúmulo diário de colmos (Fig. 4B) foi 34\% maior e a senescência diária de folhas (Fig. 5B) foi $16,4 \%$ menor comparativamente ao período de menor insolação, o que, certamente, determinou maior acúmulo líquido diário de forragem no período de maior insolação.

O potencial de utilização de forragem do capim faixa-branca foi influenciado $(\mathrm{P}<0,05)$ pelas frequências de desfolhação e pelas épocas do ano. A redução nas frequências de desfolhação diminuiu o potencial de utilização de forragem do capim faixa-branca (Fig. 8A). Por sua vez, o maior potencial de utilização de forragem foi registrado no período de maior insolação (Fig. 8B).

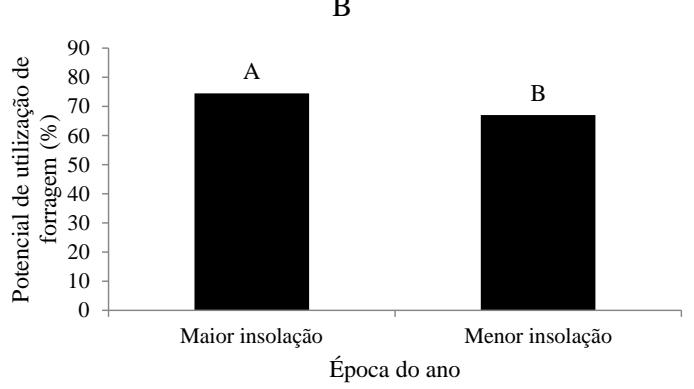

O potencial de utilização de forragem foi maior no período de maior insolação. A produção total de forragem não diferiu $(\mathrm{P}>0,05)$ entre as épocas do ano, contudo a senescência diária de folhas (Fig. 5B) foi menor no período de maior insolação, proporcionando maior potencial de utilização neste período do ano. Isso significa que, mesmo com as produções totais similares, porém com menor senescência de folhas, maior quantidade de forragem estaria disponível para o consumo animal.

De maneira geral, a frequência de desfolhação muito alta $(25 \mathrm{~cm})$ não proporcionou elevada produção diária de folhas, crescimento diário total e acúmulo total diário, demonstrando que a 
produtividade do capim faixa-branca ficou aquém do seu potencial, enquanto a baixa frequência de desfolhação, quando o dossel atingia $55 \mathrm{~cm}$, também não foi muito favorável, por não apresentar vantagem produtiva em relação à produção diária de folhas, comparativamente ao capim faixa-branca manejado com as frequências alta $(35 \mathrm{~cm})$ e média $(45 \mathrm{~cm})$. Além disso, a maior produção total e o acúmulo líquido diário com esse manejo foram resultado de elevada produção diária de colmos e senescência diária de folhas, o que indica uma acentuada queda da qualidade da forragem produzida.

\section{CONCLUSÕES}

O capim faixa-branca apresenta elevado potencial produtivo quando bem manejado, sendo uma alternativa viável para a formação de pastagens. Por sua vez, o capim faixa-branca desfolhado com alta $(35 \mathrm{~cm})$ e média $(45 \mathrm{~cm})$ frequência resulta em elevada produtividade e com composição morfológica mais adequada.

\section{AGRADECIMENTOS}

O presente trabalho foi realizado com apoio da Coordenação de Aperfeiçoamento de Pessoal de Nível Superior - Brasil (CAPES) - Código de Financiamento 001, e também do Conselho Nacional de Desenvolvimento Científico e Tecnológico (CNPq) e da Fundação de Apoio à Pesquisa e à Inovação Tecnológica do Estado de Sergipe (FAPITEC).

\section{REFERÊNCIAS}

ARAUJO, H.R.; RANGEL, J.H.A.; FAGUNDES, J.L. et al. Productive characteristics of the grass Digitaria umfolozi subjected to defoliation frequencies. Semin. Ciênc. Agrár., v.38, p.343-354, 2017.

BIRCHAM, J.S.; HODGSON, J. The influence of sward condition on rates of herbage growth and senescence in mixed swards under continuous stocking management. Grass Forage Sci., v.38, p.323-331, 1983.

CARVALHO, R.M.; SANTOS, M.E.R.; CARVALHO, B.H.R. et al. Morphogenesis of Marandu palisade grass closer to or farther from cattle feces varies by season. Semin. Ciênc. Agrár., v.37, p.3231-3242, 2016.
COOK, B.G.; SCHULTZE-KRAFT, R. Botanical name changes-nuisance or a quest for precision? Trop. Grassl. Forrajes Trop., v.3, p.34-40, 2015.

DIFANTE, G.S.; NASCIMENTO JÚNIOR, D.; SILVA, S.C. et al. Morphogenetic and structural characteristics of Marandu palisadegrass subjected to combinations of cutting heights and cutting intervals. Rev. Bras. Zootec., v.40, p.955963, 2011.

FOOD and Agriculture Organization of the United Nations. Available in: <http://faostat3.fao.org/browse/area/21/E>. Accessed in: 19 Jan. 2017.

GIMENES, F.M.A.; SILVA, S.C.; FIALHO, C.A. et al. Ganho de peso e produtividade animal em capim-marandu sob pastejo rotativo e adubação nitrogenada. Pesqui. Agropec. Bras., v.46, p.751-759, 2011.

LEMAIRE, G.; CHAPMAN, D. Tissue fluxes in grazing plant communities. In: HODGSON, J., ILLIUS, A.W. (Eds.). The ecology and management of grazing systems. Wallingford: CAB International, 1996. p.3-36.

MATTHEW, C.; ASSUERO, S.G.; BLACK, C.K. et al. Tiller dynamics of grazed swards. In: LEMAIRE, G.; HODGSON, J.; MORAES, A.P.C.F. et al. (Eds.). Grassland ecophysiology and grazing ecology. Wallingford: CABI Publishing, 2000. 432p.

MONTAGNER, D.B.; NASCIMENTO JÚNIOR, D.; SOUSA, B.M.L. et al. Morphogenetic and structural characteristics of tillers of Guinea grass of different age and grazing severities. Rev. Bras. Zootec., v.40, p.2105-2110, 2011

NASCIMENTO JÚNIOR., D.; SANTOS, M.E.R.; SILVEIRA, M.C.T. et al. Atualidades sobre manejo do pastejo nos trópicos. In: PEREIRA, O.G.; FONSECA, D.M.; OBEID, J.A. et al. (Orgs.). SIMPÓSIO SOBRE MANEJO ESTRATÉGICO DA PASTAGEM, 5., 2010, Viçosa. Anais... Viçosa: UFV, 2010. p.1-40.

NAVARRO, L.; RODRÍGUEZ, P.I.E.; GONZÁLEZ, C.S.; TORRES, D.A.R. Umfolozi o pangola peluda: um pasto que comieza a ser cutivado. INIA Divulga, [n.4, p.29-32,] 2005. 
OLIVEIRA, V.S.; MORAIS, J.A.S.; FAGUNDES, J.L. et al. Produção e composição químico-bromatológica de gramíneas tropicais submetidas a dois níveis de irrigação. Arch. Vet. Sci., v.20, p.7-36, 2015.

PAIVA, A.J.; SILVA, S.C.; PEREIRA, L.E.T. et al. Morphogenesis on age categories of tillers in Marandu palisadegrass. Sci. Agric., v.68, p.626$631,2011$.

SANTOS, M.E.R.; FONSECA, D.M.; GOMES, V.M. et al. Capim-braquiária sob lotação contínua e com altura única ou variável durante as estações do ano: morfogênese e dinâmica de tecidos. Rev. Bras. Zootec., v.40, p.2323-2331, 2011.

SBRISSIA, A.F.; SILVA, S.C. Compensação tamanho/densidade populacional de perfilhos em pastos de capim-marandu. Rev. Bras. Zootec., v.37, p.35-47, 2008.

SILVA, S.C.; NASCIMENTO JÚNIOR, D. Avanços na pesquisa com plantas forrageiras tropicais em pastagens: características morfofisiológicas e manejo do pastejo. Rev. Bras. Zootec., v.36, p.122-138, 2007.
SILVEIRA, M.C.T.; NASCIMENTO JÚNIOR, D.; RODRIGUES, C.S. et al. Forage sward structure of Mulato grass (Brachiaria hybrid ssp.) subjected to rotational stocking strategies. Aust. J. Crop Sci., v.10, p.864-873, 2016.

SOUSA, B.M.L.; NASCIMENTO JÚNIOR, D.; MONTEIRO, H.C.F. et al. Dynamics of forage accumulation in Elephant grass subjected to rotational grazing intensities. Rev. Bras. Zootec., v.42, p.629-638, 2013.

SOUZA, L.J.N.; SANTOS, D.B.O.; FAGUNDES, J.L. et al. Morfogênese do capim faixa-branca submetido a adubação nitrogenada. Bol. Ind. Anim., v.73, p.281-289, 2016.

TAIZ, L.; ZEIGER, E. Fisiologia vegetal. 4.ed. Porto Alegre: ArtMed, 2009. 848p.

VOLTOLINI, T.V.; SANTOS, F.A.; MARTINEZ, J.C. et al. Características produtivas e qualitativas do capim-elefante pastejado em intervalo fixo ou variável de acordo com a interceptação da radiação fotossinteticamente ativa. Rev. Bras. Zootec., v.39, p.1002-1010, 2010. 